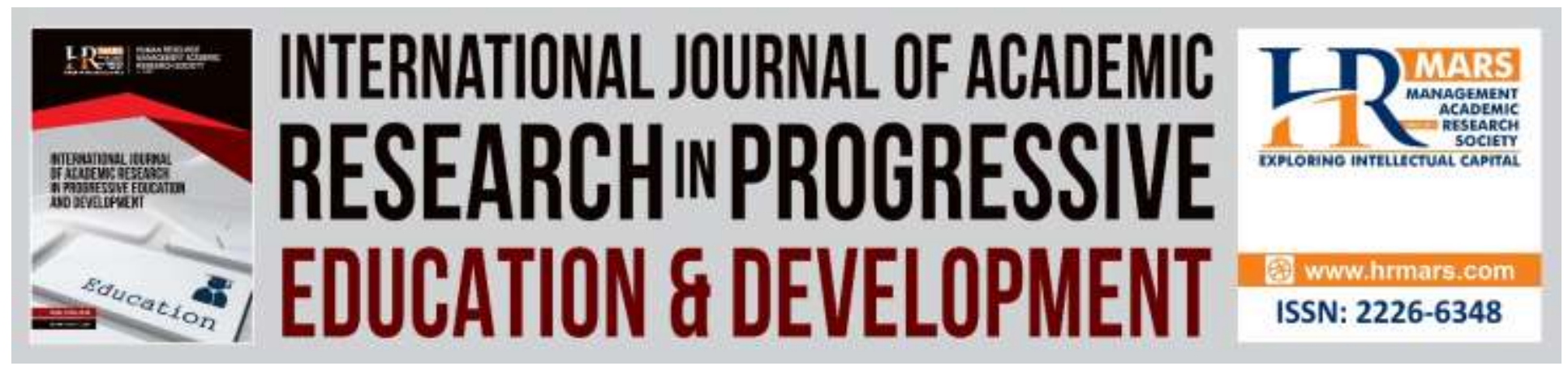

\title{
The Relationship between Libyan EFL Learners' Self-Efficacy Beliefs and Their Use of Vocabulary Learning Strategies
}

Laila Aiyad Abozaid, llyana Jalaluddin

To Link this Article: http://dx.doi.org/10.6007/IJARPED/v8-i4/6519

DOI:10.6007/IJARPED/v8-i4/6519

Received: 02 October 2019, Revised: 19 October 2019, Accepted: 29 October 2019

Published Online: 06 November 2019

In-Text Citation: (Abozaid \& Jalaluddin, 2019)

To Cite this Article: Abozaid, L. A., \& Jalaluddin, I. (2019). The Relationship between Libyan EFL Learners' SelfEfficacy Beliefs and Their Use of Vocabulary Learning Strategies. International Journal of Academic Research in Progressive Education and Development, 8(4), 312-327.

\section{Copyright: (c) 2019 The Author(s)}

Published by Human Resource Management Academic Research Society (www.hrmars.com)

This article is published under the Creative Commons Attribution (CC BY 4.0) license. Anyone may reproduce, distribute, translate and create derivative works of this article (for both commercial and non-commercial purposes), subject to full attribution to the original publication and authors. The full terms of this license may be seen at: http://creativecommons.org/licences/by/4.0/legalcode

Vol. 8(4) 2019, Pg. 312- 327

Full Terms \& Conditions of access and use can be found at http://hrmars.com/index.php/pages/detail/publication-ethics 


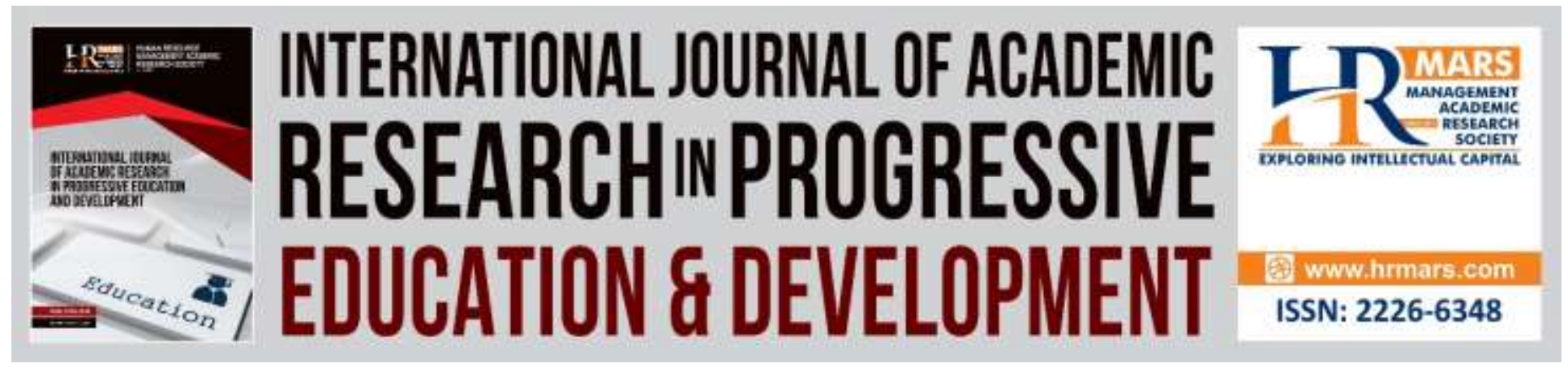

\title{
The Relationship between Libyan EFL Learners' Self-Efficacy Beliefs and Their Use of Vocabulary Learning Strategies
}

\author{
Laila Aiyad Abozaid, Ilyana Jalaluddin \\ Faculty of Modern Languages and communication, English Language Department, University \\ Putra Malaysia \\ Email: albraa.salah14@gmail.com, ilyana@upm.edu.my
}

\begin{abstract}
The recent research investigated the relationship between Libyan English as a Foreign Language (EFL) learners' beliefs and their use of Vocabulary Learning Strategies (VLSs). The respondents were 200 students studying English at Tripoli University, Faculty of Education-Janzour. The data was collected through two sets of instruments: (i) a questionnaire of vocabulary learning strategies which was designed by Schmitt (1997) to determine the frequency of VLS use and (ii) a questionnaire of Vocabulary Learning Self-Efficacy Beliefs adapted from a study conducted by Tseng (2006). Collected data was quantitatively analyzed utilizing the Statistical Package for the Social Sciences version 25. The results demonstrated that respondents of this study were medium-level users of strategy with average rating of 3.4 and standard deviation of 0.5 for overall rating use of strategy. Furthermore, the most used VLS category was determination strategies (3.74), while the category of metacognitive strategies $(M=3.16)$ was the least used among all the five VLSs used by the participants. Based on the results, learners had positive beliefs about vocabulary learning, which were significantly positively related to their use of vocabulary learning strategies ( $r=0.511)$, in generally, and the use of five subcategories, in particularly. Thus, it was found that vocabulary learning strategies use increases as the self-efficacy of students increases. Keywords: Vocabulary Learning Strategies, Frequency of Strategy Use, Self-Efficacy Beliefs

\section{Introduction}

Vocabulary is a very vital aspect of the four language skills that will enable learners to read, write, listen, and speak. With the knowledge of vocabulary, a learner can convey the meaning of his or her ideas. In Libya, English is taught as FL (Altaieb, 2013) and vocabulary is a big problem for most learners of them. Khalifa (2015) says that the main problem that learners complain about is that they cannot recall the words taught or their meanings. Another issue is orthography. Libyan learners find it difficult to spell the words correctly. In order to memorize new words, most Libyan learners normally use the word repetition strategy. For instance, they repeat the English word
\end{abstract}


aloud with its Arabic translation or write it several times on a piece of paper or notebook with the Arabic equivalent. Some of the learners feel that using only the memorisation strategy does not generate any interest or enthusiasm to learn more new words on their own. Lastly, the learners have never been exposed to training on different vocabulary learning strategies. Furthermore, research findings by other Libyan researchers have mentioned that Libyan students have a smaller vocabulary size than what has been required in the English Teaching Syllabus (Aljdee \& Orafi, 2015).

In recent years, the topic of learners' self-efficacy beliefs has gained much attention in education. Self-efficacy was first conceptualized by Bandura $(1986,1997,2007)$, who defines self-efficacy as a personal assessment of one's competency in the execution of specific behaviors or achievement of specific results in the future; thus, they need not necessarily represent a correct assessment of one's actual level of competence (as cited in Shea \& Bidjerano, 2010).In this sense, perceived self-efficacy helps to explain why people's behaviors commonly vary even if they possess comparable abilities. Delcourt and Kinzie (1993) stated that recognized self-efficacy mirrors a person's confidence in their capacity to conduct behaviors necessary for producing particular outcomes. Ormrod (2008) states that social cognitive theorists maintain that efficacy comes from one's earlier successes and failures, messages communicated by others, other people's successes and failures, and a group's successes and failures. This means that individuals decide their self-efficacy by evaluating how they have performed in past tasks, from the opinions of others on their performance, seeing how others perform, and from the results of their efforts and the achievements of group efforts in tasks that require collaborative effort.

In research on the relationship between self-efficacy and language learning strategies, Yang (1999) found students with higher levels of self-efficacy use more strategies, think more about their ability to perform specific duties, use more tactics, engage vigorously, and eventually perform better. Similarly, the connection between self-efficacy and language learning strategies was researched by Siew and Wong (2005). They revealed that pre-service educators with high self-efficacy reported using language strategies more frequently than pre-service educators with low self-efficacy. In a further study, Li and Wang (2010) studied the relationship between reading self-efficacy and the use of reading strategies. the research's results appeared that self-efficacy was significantly linked to the reading strategies' use, especially meta-cognitive strategies. They added that highly self-efficient readers reported more frequent use of reading strategies than those who were less self-effective.

Accordingly, since limited studies have been done on the relationship between students' selfefficacy beliefs and the use of vocabulary learning strategies (as shown in section 2.3), this study investigates the issue. This study seeks to identify the frequency of VLSs employed by Libyan EFL learners as well as their level of self-efficacy towards vocabulary learning. Furthermore, it attempts to investigate the relationship between VLS use and vocabulary learning self-efficacy. Therefore, in light of the objectives, the following research questions were formulated:

1) What are the VLSs employed by undergraduate Libyan students majoring in English language?

2) What is the level of Libyan university students' self-efficacy beliefs towards learning vocabulary? 
Vol. 8, No. 4, 2019, E-ISSN: $2226-6348$ @ 2019 HRMARS

3) Is there any relation between Libyan learners' self-efficacy and their use of vocabulary learning strategies?

\section{Significance of the Study}

The importance of this research is to bridge the neglected gap in research, in general, as educational research lacks studies on the relation between self-efficacy and vocabulary learning strategies. Thus, this research contributes additional knowledge to the field of learning vocabulary. It is anticipated that the findings of the current research can assist instructors improve some personality abilities for learners, such as their learners' self-efficacy beliefs to assist them learn a foreign/second language. The findings on vocabulary learning strategies also have implications in relation to which vocabulary learning strategies could be taught to poor learners. This is significant as vocabulary learning strategy instruction has been found to positively influence vocabulary learning (Zhao, 2009, as cited in Ahmad, 2016, p. 15).

\section{Literature Review}

\section{Research on Vocabulary Learning Strategies}

According to Oxford (1990), language learning strategies are certain activities employed by learners to facilitate their learning, making it faster, easier, more enjoyable, independent, and further transferable to novel situations. The utilization of learning strategies is essential in learning vocabulary and relies considerably on learners' efforts. As such, researchers have indicated a range of VLSs employed by learners (Kafipour, 2010). VLSs are a branch of language learning strategies (Abadi \& Baradaran, 2013; Zhi-Liang, 2010). VLSs are the approaches adopted by language learners to acquire new English words (Jafari \&Kafipour, 2013; Safian, Malakar \& Kalajahi, 2014; Zarrin \& Khan, 2014).

Below are some studies that have examined the way learners use VLSs. Research conducted by Soheila and Mehdi (2017) investigated the possible relationship between Iranian learners' breadth and depth of L2 vocabulary mastery and their use of cognitive and metacognitive VLSs. The participants of the research were 36 intermediate EFL students from two language institutes. The results of the research revealed that (a) cognitive vocabulary tactics were used frequently, (b) the depth and breadth of vocabulary mastery were strongly linked with cognitive and metacognitive strategies use, (c) metacognitive vocabulary strategies were found to have a stronger correlation with the two measurable kinds (depth and breadth) of vocabulary mastery, (d) the overall level of depth and breadth of vocabulary mastery connected significantly and positively with the overall level of cognitive and metacognitive strategies use. Since the vocabulary knowledge is correlated positively to cognitive and metacognitive strategies, the researcher concluded that concentration on vocabulary strategies leads to the increase of vocabulary.

Hagos and Deneke (2016) explored the VLSs employed by Ethiopian university learners majoring in English. survey and interview were the instruments for gathering relevant data for the study. A total of 134 students filled out the survey. The findings of the study indicated that the high achievers employed VLSs (determination, memory, cognitive, and meta-cognitive strategies) more frequently compared to the low achievers, but there was a lack of any significant differences in respect to the strategies. Conversely, the low achievers employed social strategies 
more frequently compared to the high achievers. However both groups of learners made less use of the social strategies. Lastly, recommendations were made for instructors to provide training to learners in the use of multifaceted VLSs to progress their academic performance and language use.

Kafipour, Yazdi, Soori, and Shokrpourcm, kjhfmhgfdh, (2011) investigated the level of vocabulary and vocabulary learning strategies of Iranian learners. The participants were 238 Iranian juniorlevel students from Semnan. Schmitt's (1997) Vocabulary Learning Strategies Questionnaire (VLSQ) and Nation's Vocabulary Level Test (VLT) were employed to gather data. The results showed that Iranian learners were in the middle-level of strategy use with an overall strategy average score of 2.99. Moreover, the findings indicated that students had sufficient vocabulary knowledge at the 2000 and 3000-word levels. However, they did not have sufficient word mastery at the 5000,10000, and academic vocabulary levels.

Hamzah, Kafipour, and Abdullah (2009) conducted a research on VLSs of Iranian learners studying EFL to indicate the relation between vocabulary size and VLSs. Their findings revealed that the participating students were moderate users of VLSs. On the other hand, they pointed to the fact that these learners had undergone and passed a study skills course in the first semester of their university studies. Moreover, a positive connection was discovered in their study among VLSs and the students' vocabulary size.

In the Libyan context, Aljdee (2011) investigated Libyan EFL learners' frequency of VLS use with a VLS questionnaire. A correlation was established for the students' answers and their outcomes in two vocabulary tests utilized to assess the vocabulary mastery for students' reception and controlled production. The results demonstrated that the students used several VLSs, albeit with low frequency. It was also revealed that with regard to the use frequency, discovery strategies scored higher than consolidation strategies. In addition, it was revealed that the learners' vocabulary knowledge and some VLSs, including the use of a monolingual dictionary, contextual guessing, listing, making of words, and media use, were very positively correlated. Furthermore, there was a clear pattern of lowering scores with regard to frequency levels in receptive and productive vocabulary knowledge and lowering average from receptive to productive knowledge. This implies that students were incapable to utilize their receptive vocabulary in productive situations.

\section{Taxonomies of Vocabulary Learning Strategy}

In past decades, researchers have introduced various language learning classifications (Ellis, 1994; O'Malley\& Chamot, 1990; Oxford, 1990; Stern, 1992). As for a Foreign Language (FL) vocabulary learning, Gu and Johnson, (1996), Schmitt (1997), and Nation (2001) introduced various classification which have proved to be the most outstanding. Among the researchers above-mentioned, Schmitt (1997) offered a detailed inventory of learning vocabulary derived from Oxford's (1990) classification of language learning strategies, that has a range of benefits, as mentioned by Jimenez-Catalan (as cited in Jafari \& Kafipour, 2013). It is more uniform and is efficient in gathering data from students. It is also relatively easy to code, classify, and manage the data in computer applications. Additionally, it can be used with different age groups who hail from various educational backgrounds and target languages, which makes it possible to compare the findings of a study with those of other studies. As such, Schmitt's taxonomy of VLSs was 
employed as an instrument for collection of the needed data from the study participants. The sections that follow will present a summary of three vocabulary learning classification by Gu and Johnson (1996), Nation (2001), and Schmitt (1997).

\subsubsection{Gu and Johnson (1996)}

Gu and Johnson (1996) studied the VLSs of advanced Chinese learners and used a questionnaire on vocabulary learning, proficiency tests, and a vocabulary size test. The questionnaire comprised two parts: one on learners' beliefs regarding learning vocabulary and the other ninety-one strategies. Based on this research, they grouped the VLSs into four major groupings: (1) "metacognitive", (2) "cognitive", (3) "memory", and (4) "activation strategies".

"Self-initiation strategies and selective attention" make up two sub-sets of metacognitive strategies. Using selective attention involves the identification of the lexical items important to the text's comprehension. Using different ways to comprehend the meaning of words is an instance of self-initiation strategies. Cognitive strategies require "guessing techniques", "consulting dictionaries", and "note-taking strategies". Memory strategies encompass "encoding and rehearsal tactics". Finally, activation strategies refer to the use of unfamiliar vocabulary in various contexts.

\section{Nation (2001)}

Different from categorizations of VLSs, Nation's (2001) classification is fully hypothetical instead of being based on any empirical evidence. Nation (2001) grouped the techniques into three broad classes: (1) "planning vocabulary learning", (2) "sources of vocabulary learning", and (3) "learning processes", with a sub-section of classification for each of them.

Planning encompasses decisions on how, where as well as how often to concentrate on words, and it consists of tactics for the selection of the words which would be most appropriate to facilitate learning, word knowledge aspects, selecting the correct techniques from a list of options, and also planning of repetition. "Consulting dictionaries" and "utilizing word cards" to determine the words' knowledge are examples of planning. "Sources of Vocabulary learning" involves seeking information regarding anew word by way of analysis of the word form itself, reference sources such as first language (L1) and L2 dictionaries and employing similarities with other learned languages, the context the word appears in. Based on what learning objectives are, such details may encompass some or all word knowledge aspects.

The third classification, "processes", involves the establishment of word knowledge from different sources or how to remember word by noticing, trying to retrieve, and producing when necessary. Nation (2001) explains that noticing means identifying the vocabulary to learn by adding it to the list of vocabulary, repeating visually and orally, and preparing flash cards. He maintains that despite the simplicity of these strategies, they are fundamental to in-depth processing of words. Retrieving entails recalling the earlier acquired words by using productive or receptive abilities, either orally or visually, within or out of the context. Generation of techniques involves the connection of novel aspects of knowledge to what is established by way of word analysis and semantic mapping.

Schmitt (1997)

As this present research this particular grouping of VLSs is discussed in detail. Schmitt examined 600 Japanese adult learners. His uses Schmitt's (1997) VLS questionnaire as one of the 
instruments, it is appropriate that research sought to identify the strategy types employed by students and which ones they deemed most beneficial. To attain the study objectives, he proposed a58-item classification of VLSs. The classification of VLSs was created on the basis of the LLS taxonomy organized by Oxford (1990), encompassing the Memory, Cognitive, Metacognitive, and Social categories. Although Oxford's taxonomy was suitable in general, it failed when categorizing "vocabulary-specific strategies" (Schmitt, 1997, p. 205) in several respects. Schmitt proposes two aspects of VLSs: "discovery strategies" and "consolidation strategies". The former are strategies for uncovering the meanings of the words the learner encounters at first glance, and students must utilize their mastery of the language or reference materials to guess the novel meanings (Determination tactics), or inquire from a person having knowledge (Social Strategies). Consolidation tactics are used to assist the learner in internalizing the meaning when he or she comes across the word later. Consolidation tactics include "cognitive", "metacognitive", "memory", and "social strategies". (Schmitt, 1997)

Determination tactics are utilized when students come across novel words attempting to determine their meanings based on structural knowledge, context, and reference materials in the absence of seeking the help of another person (Schmitt, 1997). Social strategies are found in the two categories because they can be used to both discover and consolidate a word. Social tactics are utilized in cases when the lexical items are acquired in the process of social interaction. "Seeking the help of teachers for the first language translation", "engaging in group discussions", and "asking classmates for the word meaning" are various forms of using social techniques in vocabulary acquisition. On the other hand, "studying and practicing the words in groups" and "speaking with native speakers" are further ways of using social tactics to consolidate a vocabulary.

Memory techniques entail the use of established mnemonic methods to manage or change the mental information to make it more unforgettable, like establishing a link between the new word and earlier acquired knowledge to accelerate students' learning. For instance, information can be acquired and recalled using sounds such as by "studying the sound of a word" or by using images such as "studying words by looking at pictures" representing a word's meaning, combining sounds and images by using a "keyword method", gestures of the body by "using physical actions when acquiring a word", or by "associated location" (e.g., the Loci method) (Schmitt, 1997). The cognitive and memory techniques are not easy to differentiate, but "the goal of both is to assist recall of words through some form of language manipulation" (Schmitt, 1997, p. 205). However, the focus of cognitive technique is not on the processing of manipulative mental; they consist of repetition and employing mechanical means to acquire and keep knowledge. "Verbal and written repetition", "utilizing word lists and flash cards", "note taking in class", "maintaining vocabulary notebooks", and "sticking English labels on physical objects" are some of the ways of employing cognitive techniques.

In Schmitt's (1997) classification, metacognitive techniques are known as tactics that students intentionally use to assess, have decisions, manage, and controlling their personal learning. Utilizing linguistics media to increase second language exposure; practice self-testing, that verifies the efficacy of one's choice of tactics and offers a substantial quantum of input; and avoiding and ignoring new vocabulary are examples of metacognitive tactics. Schmitt's grouping of VLSs is presented in Table 1. 
Table 1. Schmitt's (1997) classification of L2 vocabulary learning strategies

\begin{tabular}{ll}
\hline \multirow{2}{*}{ “Discovery Strategies" } & Determination Strategies \\
\cline { 2 - 2 } & Social Strategies \\
\hline \multirow{2}{*}{ “Consolidation Strategies" } & Social Strategies \\
\cline { 2 - 2 } & Memory Strategies \\
\cline { 2 - 2 } & Cognitive Strategies \\
\cline { 2 - 2 } & Metacognitive Strategies \\
\hline
\end{tabular}

Researchers like Catalan (2003) state that Schmitt's (1997) grouping of VLSs is superior to many others. It has a higher level of standardization; using it for data collection, coding and analysis is easy and uncomplicated; it can be employed for educational levels, various age groups, and new languages; its basis is based on learning and memory theories; as well as it also permit comparison with other researches. Thus, Schmitt's (1997) VLS questionnaire was adopted as a tool for the gathering of data in this research.

\section{Research on VLSs and Self-Efficacy}

Mizumoto (2012) studied how self-efficacy affected learners in their use of VLSs. The findings indicate that there is a positive correlation between the degree of self-efficiency and the learners' vocabulary size. It was also found that in VLSs, self-efficacy affected the way participants performed in their open-ended responses. The findings of text mining and correspondence analysis indicated that learners who were highly self-efficient (participants in the "Yes" response category) actively used VLSs, employing deep strategies, and showing better metacognitivity compared to those with medium and low self-efficiency. Learners with medium self-efficacy (participants in the "Not sure" category) also actively used VLSs but opted for shallow strategies in comparison with the highly self-efficient ones. The low self-efficacy learners (participants in the "No" category) had a tendency to be passive VLS users. Parallel to this context, Heidari, Izadi, and Ahmadian (2012) examined the relation between Iranian EFL juniors' beliefs and their utilize of strategies for vocabulary learning. the researchers discovered that students had a high level of beliefs towards vocabulary, that was related to their use of the sub-classification of vocabulary learning strategies generally, and the utilization of memory tactics particularly. Highly selfefficacious learners revealed significantly more use of vocabulary strategies than learners with low beliefs. Therefore, highly self-efficient learners revealed considerably great use of vocabulary tactics than low beliefs learners.

\section{Methodology}

This section includes the sampling as well as research design, data collection instruments and processing in data utilized in the present study. 
INTERNATIONAL JOURNAL OF ACADEMIC RESEARCH IN PROGRESSIVE EDUCATION AND DEVELOPMENT

Vol. 8, No. 4, 2019, E-ISSN: 2226-6348 @ 2019 HRMARS

\section{Sampling and Research Design}

The population of the present research was included of 200 Libyan EFL learners at Tripoli University, Faculty of Education-Janzor. They had been learning EFL for at least 11 years, and they were in the third, fourth and fifth semesters of university. They were selected from the population by using a homogenous purposive sampling method. The reason behind choosing the third, fourth and fifth semesters is that they had already studied vocabulary development as a subject in the first and second semesters. They would therefore be assumed to have more experience than the first-and second-semester students. As a result, they would be able to report their beliefs about learning language, in generally, and VLSs, in particularly. The research design adopted in this research is a cross-sectional survey design in which the researcher gathers the data at one point in time. This design is more pertinent in this study as "it can examine current attitudes, beliefs, and opinions" (Creswell, 2012, p. 403).

\section{Data Collection Instruments}

This research used two kinds of questionnaire to meet the goals of the study. They are as follows: 1)The Vocabulary Learning Strategies Questionnaire, composed by Schmitt (1997), was used to identify the VLSs' frequency of utilized by EFL students. Therefore, the researchers adopted Aljdee's (2008) versions (English and Arabic), which he modified and utilized to be more understandable in the Libyan context. The instrument consists of 44 items on VLSs grouped under five subcategories: determination strategies, including nine items; social strategies, including seven items; memory strategies, with 14 items; cognitive strategies, with five items; and metacognitive strategies, with nine items. The frequency of use is measured with a five-point Likert-scale, which requires students to select one of five choices: Never $0 \%$, Rarely $20 \%$, Sometimes $40 \%$, Often $60 \%$, and Always $80 \%-100 \%$.

2)The vocabulary learning self-efficacy beliefs questionnaire was adopted from Tseng (2006) with reference to a subscale, "Self-Confidence," used by Gardner, Tremblay, and Masgoret (1997). The questionnaire was used to identify the current level of Libyan learners' self-efficacy. The scale made up of 10 items on Likert-scale. The learners were required to read each item and select one of Likert's six-point responses: 1 Strongly Disagree, 2 Disagree, 3 Slightly Disagree, 4 Slightly Agree, 5 Agree, and 6 Strongly Agree. According to Tseng (2006), when a student obtains a score above three (Slightly Disagree) in vocabulary learning self-efficacy, this means that the student may have a positive belief in vocabulary learning.

\section{Processing in Data}

Descriptive statistics (for instance, mean scores, standard deviations, frequency counts, and percentages) were utilized to analyze the first and second research questions. Descriptive statistics were used to obtain information about the frequency of VLS use by the respondents and the level of respondents' self-efficacy beliefs and attitudes toward learning vocabulary. Moreover, Pearson product-moment correlations were also calculated to investigate the relationships among the respondent's self-efficacy and their use of VLSs to address the third research question. 
Vol. 8, No. 4, 2019, E-ISSN: 2226-6348 @ 2019 HRMARS

\section{Findings}

\section{Tactics for Learning Vocabulary Utilized by Undergraduate Libyan Students}

The data are presented in frequency counts and mean scores corresponding to the strategies used by the respondents in acquiring new words. The participants of this research were discovered to be medium-tactic users with a mean rate of 3.4 as well as standard deviation of 0.5 for total tactic use. This implies the convergence of the participants' responses regarding vocabulary learning strategies and non-dispersion of data from the mean rating. Table 2 presents the descriptive statistics on the use of VLSs utilized via the respondents

Table 2. Descriptive statistics for the frequencies of VLSs sub-categories employed by respondents

\begin{tabular}{lccccc}
\hline Strategy Category & Rank & N Valid & N Items & Mean & Strategy Use \\
\hline Determination Strategies & 1 & 200 & 9 & 3.74 & High \\
Memory Strategies & 2 & 200 & 14 & 3.39 & Medium \\
Social Strategies & 3 & 200 & 7 & 3.35 & Medium \\
Cognitive Strategies & 4 & 200 & 5 & 3.22 & Medium \\
Metacognitive Strategies & 5 & 200 & 9 & 3.16 & Medium \\
\hline
\end{tabular}

Table 2 presents the descriptive statistics of subcategories of VLSs employed by the respondents, which show that determination strategies $(M=3.74)$ had the greatest average score. This was followed by memory strategies $(M=3.39)$, then social and cognitive techniques $(M=3.35 ; 3.22$, respectively). Furthermore, metacognitive strategies $(M=3.16)$ had the lowest mean score among all categories of the VLSs employed by the respondents. Overall, the five categories were employed at either a high or medium level. This indicates that the learners had knowledge of all categories of vocabulary strategies.

Level of Participants' Vocabulary Learning Self-Efficacy

The participants were asked to choose responses from a six-point Likert-scale, as follows: (1) Strongly Disagree, (2) Disagree, (3) Slightly Disagree, (4) Slightly Agree, (5) Agree, and (6) Strongly Agree. According to Tseng (2006), when the students obtain a score above three (Slightly Disagree) in vocabulary learning self-efficacy, this means that those students may have a positive efficacy belief in learning vocabulary. From Table 3 it can be seen, the sum of the three last choices (i.e., Slightly Agree, Agree, and Strongly Agree) was 122, which indicates that the number of students who chose one of the last three choices was very high related to the sum of the first three choices (i.e., sum $=78$ ). This means that most of the respondents had positive beliefs about vocabulary learning. Therefore, the respondents thought they were basically finish tasks related to vocabulary. on the other hand, the mean average of the first item for the students who had negative beliefs and the students who had positive beliefs towards vocabulary were $M=26$ and 
INTERNATIONAL JOURNAL OF ACADEMIC RESEARCH IN PROGRESSIVE EDUCATION AND DEVELOPMENT

Vol. 8, No. 4, 2019, E-ISSN: 2226-6348 C 2019 HRMARS

$M=40.7$, respectively. This indicates the distance between the students' answers for the two groups and their divergence from the mean average.

Table 3. Frequency of vocabulary learning self-efficacy responses

\begin{tabular}{|c|c|c|c|c|c|c|c|c|c|c|}
\hline Item & $\begin{array}{l}\text { Strongly } \\
\text { Disagree }\end{array}$ & Disagree & $\begin{array}{l}\text { Slightly } \\
\text { Disagree }\end{array}$ & Sum & Mean & $\begin{array}{l}\text { Slightly } \\
\text { Agree }\end{array}$ & Agree & $\begin{array}{l}\text { Strongly } \\
\text { Agree }\end{array}$ & Sum & Mean \\
\hline $\begin{array}{l}\text { I feel I can } \\
\text { memorize } \\
\text { words faster } \\
\text { than others. }\end{array}$ & 11 & 34 & 33 & 78 & 26.00 & 60 & 56 & 6 & 122 & 40.67 \\
\hline $\begin{array}{l}\text { I can figure } \\
\text { out the } \\
\text { derivatives } \\
\text { of } \\
\text { vocabulary } \\
\text { easily. }\end{array}$ & 8 & 23 & 37 & 68 & 22.67 & 66 & 57 & 9 & 132 & 44.00 \\
\hline $\begin{array}{l}\text { I feel my } \\
\text { vocabulary } \\
\text { is larger } \\
\text { than others. }\end{array}$ & 13 & 55 & 38 & 106 & 35.33 & 50 & 36 & 8 & 94 & 31.33 \\
\hline $\begin{array}{l}\text { I am good at } \\
\text { vocabulary } \\
\text { tests. }\end{array}$ & 11 & 17 & 32 & 60 & 20.00 & 70 & 54 & 16 & 140 & 46.67 \\
\hline $\begin{array}{l}\text { I can usually } \\
\text { solve most } \\
\text { of the } \\
\text { vocabulary } \\
\text { problems I } \\
\text { encounter. }\end{array}$ & 10 & 24 & 28 & 62 & 20.67 & 68 & 67 & 3 & 138 & 46.00 \\
\hline $\begin{array}{l}\text { I find } \\
\text { memorizing } \\
\text { words easy. }\end{array}$ & 8 & 28 & 22 & 58 & 19.33 & 57 & 68 & 17 & 142 & 47.33 \\
\hline $\begin{array}{l}\text { learning } \\
\text { vocabulary } \\
\text { seems easy } \\
\text { for me }\end{array}$ & 12 & 20 & 32 & 64 & 21.33 & 47 & 67 & 22 & 136 & 45.33 \\
\hline $\begin{array}{l}\text { I am not } \\
\text { scared of } \\
\text { learning } \\
\text { vocabulary }\end{array}$ & 11 & 21 & 17 & 49 & 16.33 & 26 & 77 & 48 & 151 & 50.33 \\
\hline
\end{tabular}


INTERNATIONAL JOURNAL OF ACADEMIC RESEARCH IN PROGRESSIVE EDUCATION AND DEVELOPMENT

Vol. 8, No. 4, 2019, E-ISSN: 2226-6348 @ 2019 HRMARS

I have

confidence

in learning 3

vocabulary

well.
I feel my vocabulary

grades are better than

others.
11

1

$20 \quad 35$

$11.67 \quad 38$

$12 \quad 20$

35

$89 \quad 38$

$165 \quad 55.00$

\section{Relationship between Self-Efficacy of Libyan Learners and Their Utilize of Strategies for Vocabulary Learning}

Based on Table 4 outcomes, a positive moderate association through strategies for learning vocabulary and self-efficacy beliefs was found $(r=0.511, p<0.01)$. Self-efficacy was determined to have statistically positive connections with Determination Strategies $(r=0.400, p<.01)$, Social Strategies $(r=0.295, p<.01)$, Memory Strategies $(r=0.407=.824, p<.01)$, Cognitive Strategies $(r=$ $0.379, p<.01)$, and Metacognitive Strategies $(r=0.419, p<.01)$. This shows that learners' positive self-efficacy leads them to employ vocabulary strategies more often. This finding agrees with results from previous research (Heidari, Izadi, \&Ahmadian, 2012), which discovered that selfefficacy had positively relation with the utilize of the subcategories of vocabulary strategies, generally, and particularly with the utilize of memory strategies.

Table 4. Correlation coefficients of self-efficacy and strategy use of lexical items

\begin{tabular}{|c|c|c|c|c|c|c|c|}
\hline & & VLSs & DET & SOC & MEM & COG & MET \\
\hline \multirow{3}{*}{$\begin{array}{l}\text { Self- } \\
\text { Efficacy }\end{array}$} & Pearson Correlation & $.511^{* *}$ & $.400^{* *}$ & $.295^{* *}$ & $.407^{* *}$ & $.379^{* *}$ & $.419^{* *}$ \\
\hline & Sig. (2-tailed) & .000 & .000 & .000 & .000 & .000 & .000 \\
\hline & $\mathrm{N}$ & 200 & 200 & 200 & 200 & 200 & 200 \\
\hline
\end{tabular}

\section{Discussion and Conclusion}

The findings indicated that Libyan EFL university learners were in the middle -level of using vocabulary learning strategies with a mean overall strategy score of 3.4 and standard deviation of 0.5 . Furthermore, the findings of the recent research presented that undergraduate learners felt positive about completing tasks related to vocabulary. Moreover, there was a positive connection between strategies for learning vocabulary and self-efficacy.

Although in their first and second semesters, the participants had undertaken a compulsory vocabulary strategies course, questionnaire results showed that the use of different VLSs among the students was limited. These results are consistent with the findings of other researchers such 
as Hamzah, Kafipour, and Abdullah (2009) and Kafipour and Naveh (2011), whose participants had undergone and passed a study skills course in their university studies in the first semester. In both studies, the participants were in the middle level of strategy use. This may be clarified by the actuality that, in both cases, the students had undergone a study skills course earlier on, which gave them an advantage over other students without such previous exposure to the English language. It is also pertinent to note that in the case of both Libyan and Iranian EFL learners, English was considered as a foreign language rather than as a second language as it is, for example, in Malaysia. It appeared that the average student was not very enthusiastic about deriving benefit from the techniques. This may be due to several reasons. First, the learners had already used a number of tactics that they found effective and therefore they ignored learning and utilizing the rest. Second, some students used strategies unconsciously, causing them to forget to write down these strategies when filling in the survey. The participants in this study were given a program to learn vocabulary strategies, as explained earlier. This program was conducted over fourteen weeks for two hours a week, only. This was probably not enough neither suitable time for the material taught in the first undergraduate year. Where the course content has been taught at a very late level of education and only for two semesters. Therefore, the researchers recommended the policy makers should take into consideration that strategies for learning vocabulary have to be taught at early ages (i.e. at secondary school level).

Pajares (2003) claimed that most of the difficulties of students are due to their beliefs. EFL instructors should therefore raise students' self-efficacy in vocabulary strategies as this will increase their stimulation to learn, and this, in turn, contributes to their performance. Zimmerman (1990) pointed out that strategies for learning have been connected to the progress of self-efficacy leading to anticipation of success in learning. These findings indicate that there is an impact of self-efficacy on the use of vocabulary learning strategies and that efficiency of tactics for learning vocabulary can be increased through enhancing self-efficacy. It is therefore recommended that EFL instructors exploit this solid foundation (positive beliefs towards vocabulary) and provide the learners with the materials that will cement these building blocks to achieve effective language learning. This implies that positive self-efficacy in vocabulary leads learners to learn more vocabulary and use it productively in writing and speaking. As Bandura (1997) proposed, people who possess a high level of self-efficacy believe that they can execute tasks well, which later acts as an incentive for them to perform activities even in adverse situations. In contrast, negative self-efficacy leads learners to depend only on their teachers. As a result, learners keep in mind only vocabulary they are asked by teachers to memorize. In this way, learners only fulfil the needs of the teachers that may influence their perception of their roles in learning English. Thus, instructors have to identify self-efficacy for learners' vocabulary, which is the perception of vocabulary that can develop better comprehension to further their possibility of succeeding in an academic area.

The current research contributes to the review of literature, by providing a guide to the relationship between vocabulary learning strategies use and vocabulary learning self-efficacy. Therefore, this research contributes to the field of learning vocabulary by investigating the relation between vocabulary learning strategies and EFL Learners' Self-Efficacy Beliefs in the Libyan context. It, thus, provides an investigation considered as widening for limited prior studies 
Vol. 8, No. 4, 2019, E-ISSN: $2226-6348$ @ 2019 HRMARS

in this field. Consequently, information gained from this study may be used as a database for future reference, widening the scope of further academic research.

\section{References}

Abadi, A., \& Baradaran, A. (2013). The relationship between learner autonomy and vocabulary learning strategies in Iranian EFL learners with different language proficiency level. International Journal of Applied Linguistics and English Literature, 2(3), 176-185.

Ahmad, H. (2016). English vocabulary size and vocabulary learning strategies of UiTM prediploma students (Master's thesis). Universiti Kebangsaan Malaysia. Malaysia.

Aljdee, A. A. (2008). The vocabulary learning strategies of Libyan university students of English and their vocabulary knowledge (Doctoral dissertation).University of Newcastle.UK.

Aljdee, A. A. (2011). The relationship between vocabulary learning strategies and vocabulary knowledge. The American University of Cairo, TESOL Journal. Special Issue.

Aljdee, A., and Orafi, S., (2015). Vocabulary Learning Strategies and Vocabulary Knowledge among EFL Tertiary Learners: Match or Mismatch? Global Libyan Journal Vol.4,December, 2015.

Altaieb, S. (2013). Teachers' Perception of the English Language Curriculum in Libyan Public Schools: An Investigation and Assessment of Implementation Process of English Curriculum in Libyan Public High Schools. Electronic theses and Dissertations.

Bandura, A. (1997). Self-Efficacy: The Exercise of Control. Macmillan.

Catalan, R. (2003). Sex Differences in 12 Vocabulary Learning Strategies. International Journal of Applied Linguistics, 13(1), 54-77.

Creswell, J.W. (2012). Educational research: Planning, conducting, and evaluating quantitative and qualitative research. Upper Saddle River, NJ: Pearson Education International.

Delcourt, M. A. B., \& Kinzie, M. B. (1993). Computer technologies in teacher education: The measurement of attitudes and self-efficacy. Journal of Research and Development in Education, 27(1), 35-41.

Ellis, N. C. (1994). Implicit and explicit language learning: An overview in N.C. Ellis (ed.): Implicit and Explicit Learning of Languages. London: Academic Press,1-32

Gardner, R. C., Tremblay, P. F., \& Masgoret, A.-M. (1997). Towards a full model of second language learning: An empirical investigation. The Modern Language Journal, 81, 344-362.

Gu, Y., \& Johnson, R. K. (1996). Vocabulary learning strategies and language learning outcomes. Language Learning, 46(4), 643-679.

Hagos, H. B., \& Deneke, D. G. (2016). A comparative analysis of vocabulary learning strategies used by high and low achievers (A case study on undergraduate English major students in Ethiopian university). International Journal of Current Research, 8(2), 27051-27060.

Hamzah, M., Kafipour, R., \& Abdullah, S. K. (2009). Vocabulary learning strategies of Iranian undergraduate EFL students and its relation to their vocabulary size. European Journal of Social Sciences, 11(1), 39-50.

Heidari, F., Izadi, M., \& Ahmadian, M. V. (2012). The Relationship between Iranian EFL Learners' self-efficacy beliefs and use of vocabulary learning strategies. English Language Teaching, 5(2), 174-182. 
INTERNATIONAL JOURNAL OF ACADEMIC RESEARCH IN PROGRESSIVE EDUCATION AND DEVELOPMENT

Vol. 8, No. 4, 2019, E-ISSN: 2226-6348 @ 2019 HRMARS

Jafari, S., \& Kafipour, R. (2013). An investigation of vocabulary learning strategies by Iranian EFL students in different proficiency levels. International Journal of Applied Linguistics and English Literature, 2(6), 23-27.

Kafipour, R. (2010). Vocabulary learning strategies, vocabulary knowledge and reading comprehension of EFL undergraduate students in Iran (Doctoral dissertation). Universiti Putra Malaysia.

Kafipour, R., Yazdi, M., Soori, A., Shokrpour, N. (2011). Vocabulary levels and vocabulary learning strategies of Iranian undergraduate students. Studies in Literature and Language, 3(3), 6471.

Khalifa, S. (2015). Effect of Vocabulary learning Strategies on Academic Achievements of PreUniversity Libyan EFL Learners. Arab World English Journal, 6(1), 378-396.

Li, Y., \& Wang, C. (2010). An empirical study of reading self-efficacy and the use of reading strategies in the Chinese EFL context. The Asian EFL Journal Quarterly, 12(2), 144-162.

Mizumoto, A. (2012). Exploring the effects of self-efficacy on vocabulary learning strategies. Studies in Self-Access Learning Journal, 3(4), 423-437.

Nation, I. S. (2001). Learning vocabulary in another language. Ernst Klett Sprachen.

Ormrod, J. (2008). Human Learning. New Jersey, NY: Pearson Education, Inc.

O'Malley, J. \& Chamot, A. (1990). Learning strategies in second language acquisition. Cambridge, England: Cambridge University Press.

Oxford, R. L. (1990). Language learning strategies: What every teacher should know. New York, NY: Newbury House.

Pajares, F. (2003). Self-efficacy beliefs, motivation, and achievement in writing: A review of the literature. Reading and Writing Quarterly, 19, 139-158.

http://dx.doi.org/10.1080/10573560390143085

Richards, J. C. (1976). The role of vocabulary learning. TESOL Quarterly, 10, 77-89.

Safian, N., Malakar, S., \& Kalajahi, S. (2014). Exploring vocabulary learning strategies used by UPM TESL undergraduates. Advances in Language and Literary Studies, 5(5), 1-4. http://dx.doi.org/10.7575/aiac.alls.v.5n.5p.1

Schmitt, N. (1997). Vocabulary learning strategies. In N. Schmitt \& M. McCarthy (Eds.), Vocabulary: Description, acquisition and pedagogy. New York, NY: Cambridge University Press.

Shea, P., \& Bidjerano, T. (2010). Learning presence: Towards a theory of self-efficacy, selfregulation, and the development of a communities of inquiry in online and blended learning environments. Computers \& Education, 55(4), 1721-1731.

Siew, L., \& Wong, M. (2005). Language learning strategies and language self-efficacy: Investigating the relationship in Malaysia. Eric Journal, 36(3), 245-269.

Soheila, M., \&Mehdi, D. (2017). Relationship between Iranian intermediate EFL Learners' depth and breadth of lexical knowledge and their use of cognitive and metacognitive vocabulary learning strategies. Journal of Applied Linguistics and Language Research, 4(7), 260-277.

Stern, H. H. (1992). Issues and options in language teaching (Edited posthumously by Patrick Allen \& Birgit Harley). Oxford, England: Oxford University Press.

Tseng, W. T. (2006). Motivation, self-regulation and vocabulary acquisition: a structural equation modelling analysis (Doctoral dissertation). University of Nottingham. UK. 


\section{INTERNATIONAL JOURNAL OF ACADEMIC RESEARCH IN PROGRESSIVE EDUCATION AND}

DEVELOPMENT

Vol. 8, No. 4, 2019, E-ISSN: 2226-6348 ๑ 2019 HRMARS

Yang, N. D. (1999). The relationship between EFL learners' beliefs and learning strategy use. System, 27(4), 515-535.

Zarrin, S., \& Khan, Z. (2014). A study of vocabulary learning strategies among undergraduate learners of AMU. US China Foreign Language, 12, 75-82.

Zhao, J. (2009). Language learning strategies and English proficiency: A study of Chinese undergraduate programs in Thailand. Scholar: Human Sciences, 1(1).

Zhi-liang, L. (2010). A Study on English Vocabulary Learning Strategies for Non-English Majors in Independent College. Cross-Cultural Communication, 6(4), 152.

Zimmerman, B. J. (1990). Self-regulating academic learning and achievement: The emergence of a social cognitive perspective. Educational Psychology Review, 2, 173-201. 